\title{
A Special Thanks to the Reviewers of Diabetes Care
}

Diabetes Care calls on thousands of scientific and medical experts each year to review manuscript submissions. The editors of Diabetes Care sincerely appreciate the efforts of all of our reviewers, who volunteer their time and expertise to provide valuable feedback to ensure the consistently high quality of the research published in each issue. The names of every reviewer are too numerous to list here, but we would like to recognize the "top" reviewersbased on the number of reviews completed, timeliness, reliability, and quality - for their outstanding contributions and dedication to Diabetes Care.

\section{Top 12 Reviewers in 2012}

Charles M. Alexander, MD, FACP, FACE, CPI (Hon)

Angelo Avogaro, MD, PhD

Katharine Barnard, CPsychol, AFBPsS

Joshua Barzilay, MD

Gianni Bellomo, MD

Zachary Bloomgarden, MD

Rakesh Chibber, PhD

Eli A. Friedman, MD

Harry Keen, MD, FRCP*

Mark E. Molitch, MD

Giovanni Targher, MD

Deborah Wexler, MD, MSc

Thank you,

William T. Cefalu, MD

Editor in Chief, Diabetes Care

*Since the writing of this acknowledgment, we are saddened by the death of a true supporter of Diabetes Care, Dr. Harry Keen. The time and effort he devoted to the journal and, in particular, to his reviews were truly appreciated. A special tribute to both Dr. Keen and Dr. Richard Rubin, who also recently passed away, will be featured in an upcoming issue of Diabetes Care. 